\title{
North Atlantic climate responses to perturbations in Antarctic Intermediate Water
}

\author{
Jennifer A. Graham • David P. Stevens • \\ Karen J. Heywood $\cdot$ Zhaomin Wang
}

Received: 10 December 2009/Accepted: 20 December 2010/Published online: 7 January 2011

(C) Springer-Verlag 2011

\begin{abstract}
Recent observations suggest Antarctic Intermediate Water (AAIW) properties are changing. The impact of such variations is explored using idealised perturbation experiments with a coupled climate model, HadCM3. AAIW properties are altered between 10 and $20^{\circ} \mathrm{S}$ in the South Atlantic, maintaining constant potential density. The perturbed AAIW remains subsurface in the South Atlantic, but as it moves northwards, it surfaces and interacts with the atmosphere leading to density anomalies due to heat exchanges. For a cooler, fresher AAIW, there is a significant decrease in the mean North Atlantic sea surface temperature (SST), of up to $1^{\circ} \mathrm{C}$, during years 51-100. In the North Atlantic Current region there are persistent cold anomalies from 2,000 $\mathrm{m}$ depth to the surface, and in the overlying atmosphere. Atmospheric surface pressure increases over the mid-latitude Atlantic, and precipitation decreases over northwest Africa and southwest Europe. Surface heat flux anomalies show that these impacts are caused by changes in the ocean rather than atmospheric forcing. The SST response is associated with significant changes in the Atlantic meridional overturning circulation (MOC). After 50 years there is a decrease in the MOC that persists for the remainder of the simulation, resulting from
\end{abstract}

J. A. Graham $(\bowtie) \cdot$ K. J. Heywood

School of Environmental Sciences,

University of East Anglia, Norwich NR4 7TJ, UK

e-mail: j.graham@uea.ac.uk

D. P. Stevens

School of Mathematics, University of East Anglia,

Norwich NR4 7TJ, UK

Z. Wang

British Antarctic Survey, High Cross,

Madingley Road, Cambridge CB3 0ET, UK changes in the column-averaged density difference between $30^{\circ} \mathrm{S}$ and $60^{\circ} \mathrm{N}$. Rather than showing a linear response, a warmer, saltier AAIW also leads to a decreased MOC strength for years 51-100 and resulting cooling in the North Atlantic. The non-linearity can be attributed to opposing density responses as the perturbed water masses interact with the atmosphere.

Keywords Antarctic Intermediate Water . Perturbation · Atlantic

\section{Introduction}

Antarctic Intermediate Water (AAIW), characterised by a salinity minimum at depth, is found in each of the three main ocean basins-Atlantic, Pacific and Indian. It is believed that the cool, fresh water mass is formed primarily in the southeast Pacific and southwest Atlantic (eg. McCartney 1977; Piola and Gordon 1989). McCartney (1977) suggests that AAIW forms along with Subantarctic Mode Water (SAMW), through deep winter convection around the path of the Antarctic Circumpolar Current (ACC), with the coolest, freshest water resulting in the southeast Pacific and southwest Atlantic. Further studies have shown that cross-frontal mixing also plays an important role in the formation process (eg. Molinelli 1981; Piola and Gordon 1989), although there is still uncertainty over the relative importance of the mechanisms (Sloyan and Kamenkovich 2007).

Observations have shown that the properties of the ocean are changing along with our changing climate. A freshening trend has been observed in both the Pacific and Indian Ocean intermediate waters (Wong et al. 1999; Bindoff and McDougall 2000; Aoki et al. 2005). Wong 
et al. (1999) showed that there had been a cooling and freshening of the salinity minimum in the South Pacific, with a mean freshening of 0.02 in the AAIW layer. They also noticed a freshening trend in the North Pacific Intermediate Water (NPIW), providing evidence for increased precipitation at high latitudes. In the Indian Ocean, Bindoff and McDougall (2000) showed that there had been a cooling and freshening of AAIW between the 1960s and 1987 , along a section at $32^{\circ} \mathrm{S}$. This was attributed to warming of surface waters and an increased hydrological cycle, both signatures of anthropogenic climate change (Banks and Bindoff 2003). However, Bryden et al. (2003) showed that between 1987 and 2002, the upper thermocline mode waters along this same section had become saltier, reversing the previous trend. This demonstrates that more frequent observations are needed to determine whether changes observed on such sections lie within the range of internal variability, or are part of a long-term trend.

In the Atlantic Ocean, recent observations have not shown a consistent trend. The Intergovernmental Panel on Climate Change (IPCC) Fourth Assessment Report (AR4) pointed towards a general freshening trend, with Curry et al. (2003) providing the evidence for the Atlantic Ocean. Their results, from a transect between $50^{\circ} \mathrm{S}$ to $60^{\circ} \mathrm{N}$, show a freshening of 0.02 in AAIW towards the southern end of the section between the late 1950s and 1990s. However, Arbic and Owens (2001) have shown an increased salinification, along with a general warming of $0.5^{\circ} \mathrm{C}$ century ${ }^{-1}$, in Atlantic intermediate waters $(1,000-2,000 \mathrm{db})$. The results shown by Arbic and Owens (2001) cover a wider range of longitudes in the Atlantic than those of Curry et al. (2003), but only extend between $32^{\circ} \mathrm{S}$ and $48^{\circ} \mathrm{N}$. Therefore, they may not capture more recent changes in AAIW and its surface formation regions, which would be seen further south. The freshening observed by Curry et al. (2003) occurs south of $15^{\circ} \mathrm{S}$, with more saline intermediate waters further north. It should also be noted that the salinity trends shown by Arbic and Owens (2001) are acknowledged to be less significant than their temperature results, and Curry et al. (2003) do not present any significant temperature trends for AAIW.

Although some of the observational evidence may appear to be conflicting, the IPCC AR4 models have shown that this water mass is likely to change by the end of the century as we see changes in the atmospheric properties in the surface formation regions (Sen Gupta et al. 2009). However, previous studies have not focussed on how these changes may feed back within the climate system. An understanding of what impact changes in the oceans may have on the atmosphere is crucial to our understanding of how the climate will change in the future. Saenko et al. (2003) investigated the impact of a large freshwater flux in the region of enhanced
AAIW production, using an intermediate complexity model. They showed that the resulting changes in relative density of the water masses in the Atlantic could result in a shift in the Atlantic overturning circulation, between two stable 'off' and 'on' states. The study presented here uses a global coupled model of higher resolution and a density-compensating perturbation at depth in the Atlantic. The aim of this study is to investigate what impact changes in AAIW may have on climate as the perturbed water mass spreads northwards through the ocean. This paper presents the results from a pair of perturbation experiments with either a cooler, fresher or warmer, saltier Atlantic AAIW. Section 2 provides a model description and experimental set-up, followed by results for the cooling, freshening experiment presented in Sect. 3. Section 4 summarises the results from the second experiment, with warmer, saltier AAIW. Discussion and conclusions are then given in Sect. 5.

\section{Model and perturbation}

The model used for this study is HadCM3, a coupled ocean-atmosphere climate model from the Hadley Centre (Gordon et al. 2000). The atmosphere has a resolution of $2.5^{\circ} \times 3.75^{\circ}$ and 19 vertical levels. The ocean has a resolution of $1.25^{\circ} \times 1.25^{\circ}$ and 20 vertical levels. This model is able to reproduce a stable climate without the need for flux adjustments (Gordon et al. 2000). The internal climate variability of the model is discussed by Collins et al. (2001). Pardaens et al. (2003) show that HadCM3 has an enhanced freshwater cycle, likely a result of overly strong Hadley and Walker circulations. Increased freshening at high latitudes impacts on the upper ocean stratification and limits the development of deep winter mixed layers. For this reason, the AAIW is shallower and fresher than seen in both observations and some other climate models (Sloyan and Kamenkovich 2007). Here, we use HadCM3 to perform a set of idealised perturbation experiments to investigate the potential impact of changes in Atlantic AAIW on the climate of the North Atlantic.

Model Atlantic AAIW properties were perturbed at depth between 10 and $20^{\circ} \mathrm{S}$ (Fig. 1) in the South Atlantic, far removed from the water mass formation and subduction regions. The perturbation experiment allows us to focus on the impact of AAIW on the surface waters and climate as it moves northwards into the Atlantic Ocean. The salinity minimum in the Atlantic is centred on level 11 (447-666 $\mathrm{m}$ ) in the model, so the potential density is calculated with reference to this depth, using the equation of state from HadCM3. By analysing the potential temperature-salinity $(\theta-\mathrm{S})$ diagrams of the chosen perturbation region, the 


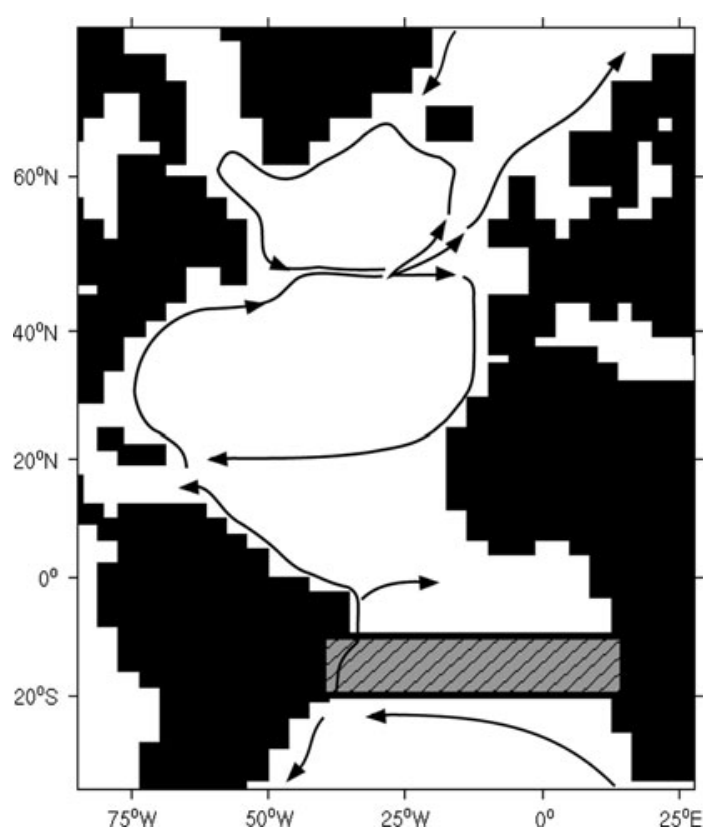

Fig. 1 Schematic to show the perturbed region of the Atlantic in HadCM3, $10-20^{\circ} \mathrm{S}$. Arrows show the mean locations of the strongest currents $\left(>1 \mathrm{~cm} \mathrm{~s}^{-1}\right)$ at $\sim 500 \mathrm{~m}$ (level 11 in HadCM3, the depth of the salinity minimum in the perturbed region). Resolution of the coastline is $2.5^{\circ} \times 3.75^{\circ}$, matching the resolution of the atmospheric component

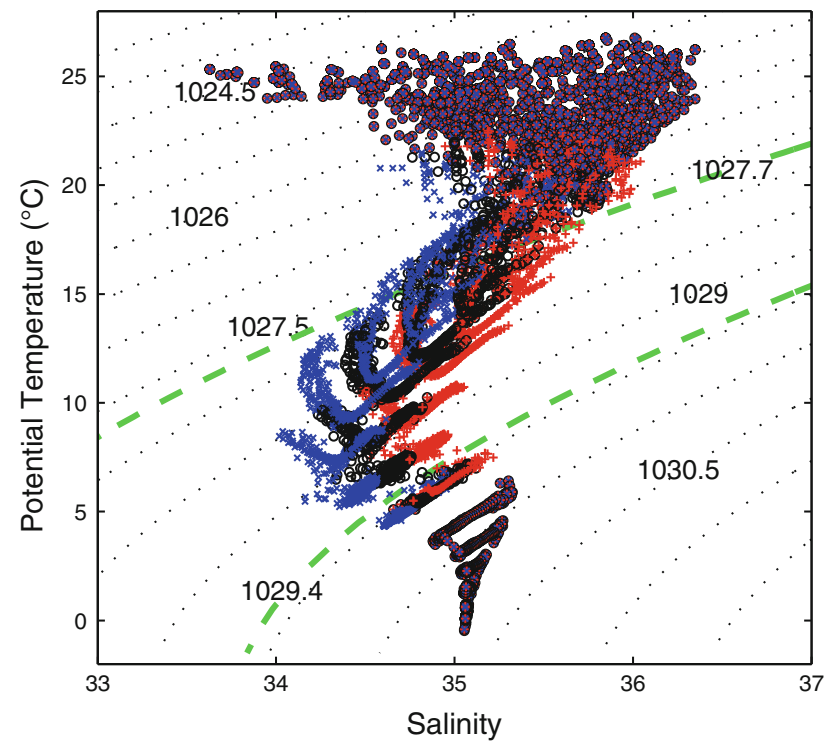

Fig. $2 \theta$-S plot for perturbation and control start dumps. Blue crosses and red plusses show the conditions for the $-1^{\circ} \mathrm{C}\left(\mathrm{EXP}^{-}\right)$and $+1^{\circ} \mathrm{C}$ $\left(\mathrm{EXP}^{+}\right)$perturbations respectively. Black circles show the control conditions. Black dotted contours show the corresponding potential density values calculated relative to a depth of $\sim 500 \mathrm{~m}$. Green contours show the boundaries of AAIW, 1,027.7 and 1,029.4

potential density range of Atlantic AAIW was chosen to be 1,027.7-1,029.4. This encompasses the salinity minimum at depth in the water column (green isopycnals in Fig. 2).
A perturbation of $\pm 1{ }^{\circ} \mathrm{C}$ was applied to all points within $10-20^{\circ} \mathrm{S}$ that lie within the chosen density boundaries for AAIW. A density-compensating perturbation was then also applied to the salinity, giving an average change of \pm 0.2 in the core of the water mass, substantially larger than the decrease of 0.02 reported by Curry et al. (2003). Maintaining a constant density ensures that the dynamics in the model are unaffected (unlike the freshwater perturbations carried out by Saenko et al. 2003). This perturbation then allows AAIW to initially follow its usual paths of circulation (until ocean-atmosphere interactions result in density anomalies due to heat exchanges). A perturbation of $\pm 0.5^{\circ} \mathrm{C}$, along with the corresponding salinity change, was also made in the levels directly above and below the AAIW region, allowing for a smoother transition in the water column. The resulting $\theta-\mathrm{S}$ curves for the perturbed region are shown in Fig. 2, with the perturbed values shown in blue (red) for the $-1^{\circ} \mathrm{C}\left(+1^{\circ} \mathrm{C}\right)$ experiment, and the control values shown in black. The average temperature and salinity in the core of the water mass between 10 and $20^{\circ} \mathrm{S}$ in the Atlantic are $8.89^{\circ} \mathrm{C}$ and 34.58 , with standard deviations of $0.04^{\circ} \mathrm{C}$ and 0.01 respectively over the 120 year control ensemble. The imposed changes in temperature and salinity are therefore both much larger than the internal temporal variability in the model. For the cooler, fresher experiment, the total heat removed from this region is $2.54 \times 10^{22} \mathrm{~J}$. The magnitude of this change is $18 \%$ of the increase reported by Levitus et al. (2005) for the top 3,000 $\mathrm{m}$ of the ocean globally between 1955 and $1998\left(14.2 \pm 2.4 \times 10^{22} \mathrm{~J}\right)$. The total loss of salt is $1.25 \times 10^{15} \mathrm{~kg}$. Whilst this is a substantial perturbation to the heat and salt content of the water mass, choosing a $1{ }^{\circ} \mathrm{C}$ change maintains the characteristic salinity minimum of the water mass during the warming perturbation. Sen Gupta et al. (2009) show that in the Polar Frontal Zone, the IPCC AR4 models project changes of up to $+1^{\circ} \mathrm{C}$ in the upper $1,000 \mathrm{~m}$ of the ocean by the end of the 21 st century. They also show freshening of up to 0.1 in this region of AAIW formation. Although no quantitative analysis is given of changes in AAIW on isopycnals, such as that used in Bindoff and McDougall (2000), this shows that our perturbations may not be far outside the magnitude of projected changes over centennial timescales.

These initial conditions are used for two 120 year integrations, with 9 ensemble members in the perturbed (hereafter referred to as $\mathrm{EXP}^{-}$and $\mathrm{EXP}^{+}$, for $-1^{\circ} \mathrm{C}$ and $+1^{\circ} \mathrm{C}$ ) and control simulations. Each of the ensemble members has identical initial ocean conditions, but different initial atmospheric conditions. The interaction of these differing atmospheres with the ocean surface provides a spread of internal variability in the ensemble. The anomalies shown in this paper are calculated as the mean of the control ensemble subtracted from the mean of the $\mathrm{EXP}^{-}$or 
$\mathrm{EXP}^{+}$ensemble, for each given time period. Significant results are defined as those statistically significant at the 95\% level, determined using a paired t-test.

\section{Response to a cool, fresh anomaly}

\subsection{Where does the anomalous water go?}

Heat and salt spread by advection and diffusion at equal rates in the model by definition, along the same paths, maintaining approximately constant density. It is only in the far North Atlantic that stronger anomalies are seen at depth in the density field, as the perturbed water mass has gained heat but remains fresh. The temperature, salinity and density anomalies for 41-50 years into the simulation (Fig. 3) demonstrate that the spread of heat and salt is comparable, resulting in approximately constant density at
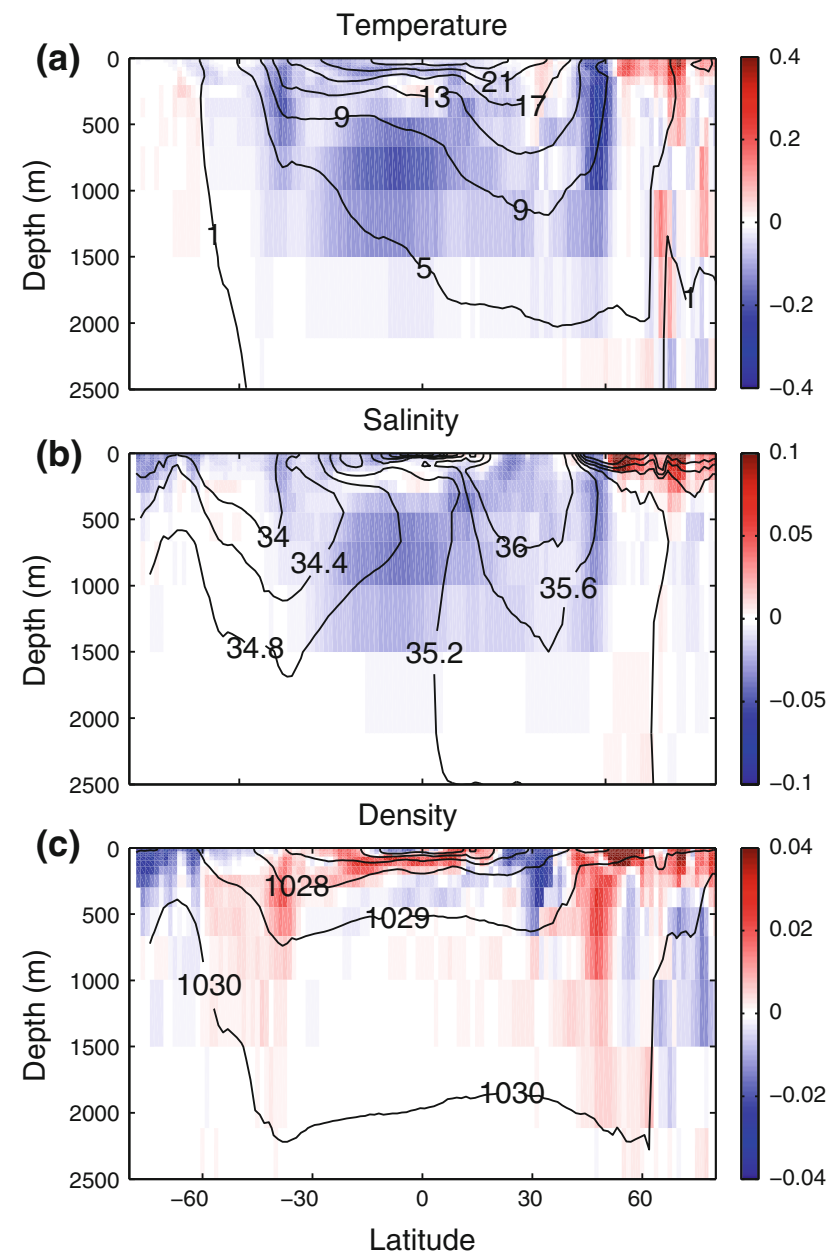

Fig. 3 Zonal average decadal anomalies $\left(\mathrm{EXP}^{-}-\mathrm{control}\right)$ in the Atlantic for years 41-50: a temperature $\left[{ }^{\circ} \mathrm{C}\right], \mathbf{b}$ salinity and $\mathbf{c}$ potential density calculated relative to a depth of $\sim 500 \mathrm{~m}$. Contours show control conditions for years $41-50$ intermediate depths in the tropical Atlantic $\left(30^{\circ} \mathrm{S}-30^{\circ} \mathrm{N}\right)$. Changes arise when the water mass comes into contact with the atmosphere. Surfacing temperature anomalies can drive an atmospheric response, which can act to reduce the anomaly by increasing atmosphere-to-ocean heat fluxes. However, there is no direct atmospheric response to salinity changes, and previous studies suggest that this feedback is weak (Hughes and Weaver 1996). Therefore, salinity, or salt content, can be used as a tracer for the perturbed water mass.

Figure 4 shows the column-integrated salt anomalies resulting from the perturbation. The path of the cooler, fresher AAIW can be traced using the reduction in salt content. After 10 years, the fresher water mass is seen to have spread northwards, being carried primarily by the North Brazil Current. From the tropical North Atlantic, the anomaly is carried further northwards with the Gulf Stream. This path of northward transport, along the western boundary, is consistent with both observations and previous modelling studies (eg., Suga and Talley 1995; Sen Gupta and England 2007; Sijp and England 2008). The mean locations of these currents are illustrated in Fig. 1. Figure 5 shows the total salt anomalies along the western boundary of the North Atlantic basin, from Florida to Baffin Bay $\left(28-75^{\circ} \mathrm{N}\right)$. The salt anomalies travel northwards at a speed consistent with advection, taking $\sim 2$ years to reach the North Atlantic Current (NAC) due to current speeds $>6 \mathrm{~cm} \mathrm{~s}^{-1}$ in the Gulf Stream (Fig. 5a). From the NAC, a portion is recirculated in the subtropical gyre, and the remainder travels further north (Fig. 4). Recirculation allows the North Atlantic to gradually fill with the fresher water mass. Significant cool, fresh anomalies are found in the region of the NAC after 30 years. During years 25-50, the anomalies along the western boundary show the northward transport of the fresher water mass (Fig. 5b) and the majority of the Atlantic basin has a reduced salt content after 50 years (Fig. 4). However, as the integration progresses, the northward branch of the NAC allows the fresher water to be carried into the subpolar gyre (SPG) and the Greenland, Iceland and Norwegian (GIN) Seas. Anomalies gradually reduce in the North Atlantic as the cooler, fresher water builds up further northwards. This can be seen in Fig. 4 for 71-80 years onwards. After 100 years, the majority of the Atlantic remains fresher than the control simulation. It should be noted that a significant volume of fresher water does stay in the initial perturbation region and recirculates in the South Atlantic.

Although it is clear that the perturbation spreads significantly in the horizontal direction, there does not appear to be much spread vertically. Figure 6 shows the zonally averaged salinity in the Atlantic. The portion of the anomaly that is initially in the upper layers disperses 


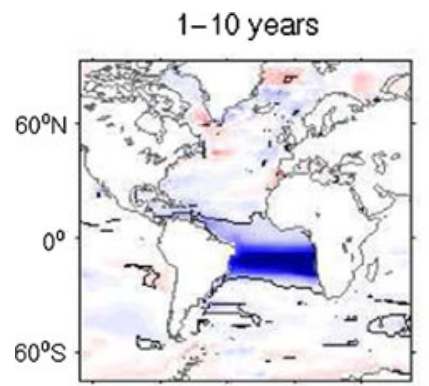

$21-30$ years

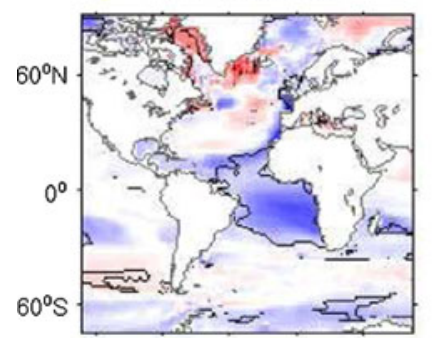

$41-50$ years

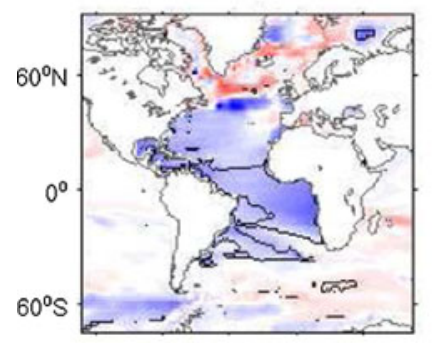

$61-70$ years

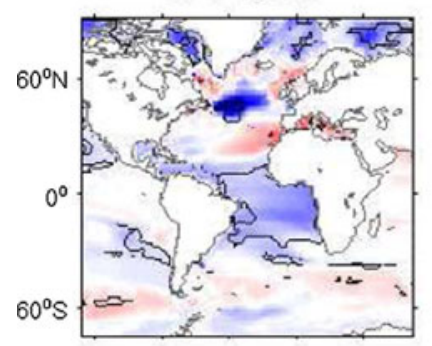

$81-90$ years
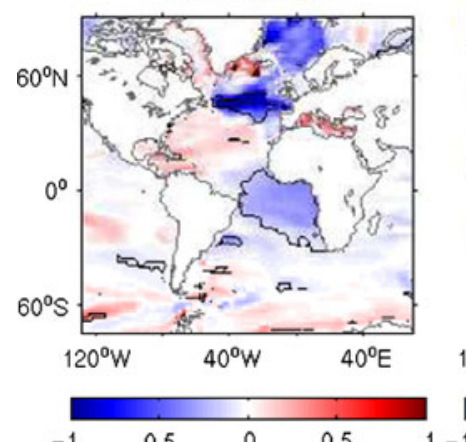

$11-20$ years

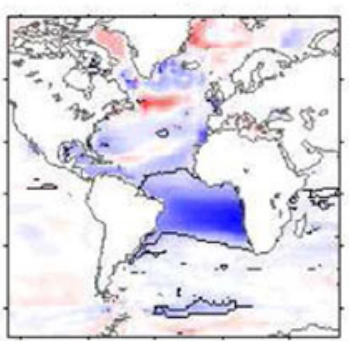

$31-40$ years

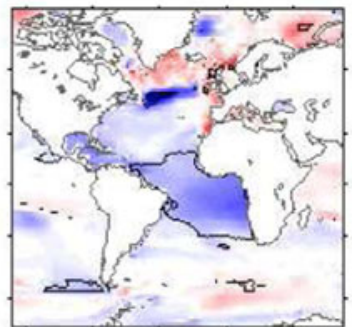

$51-60$ years

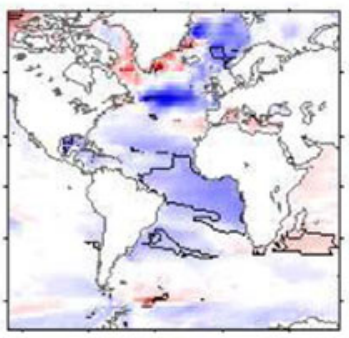

$71-80$ years

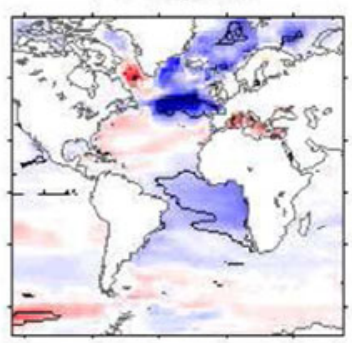

$91-100$ years

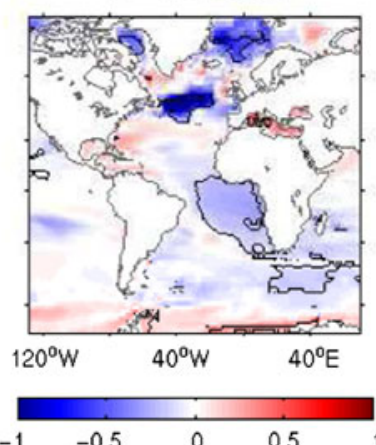

Fig. 4 Decadal salt content anomalies within columns $\left(\mathrm{EXP}^{-}-\right.$ control) $\left[\times 10^{2} \mathrm{~kg} \mathrm{~m}^{-2}\right]$. Black contours show anomalies significant at the $95 \%$ confidence level
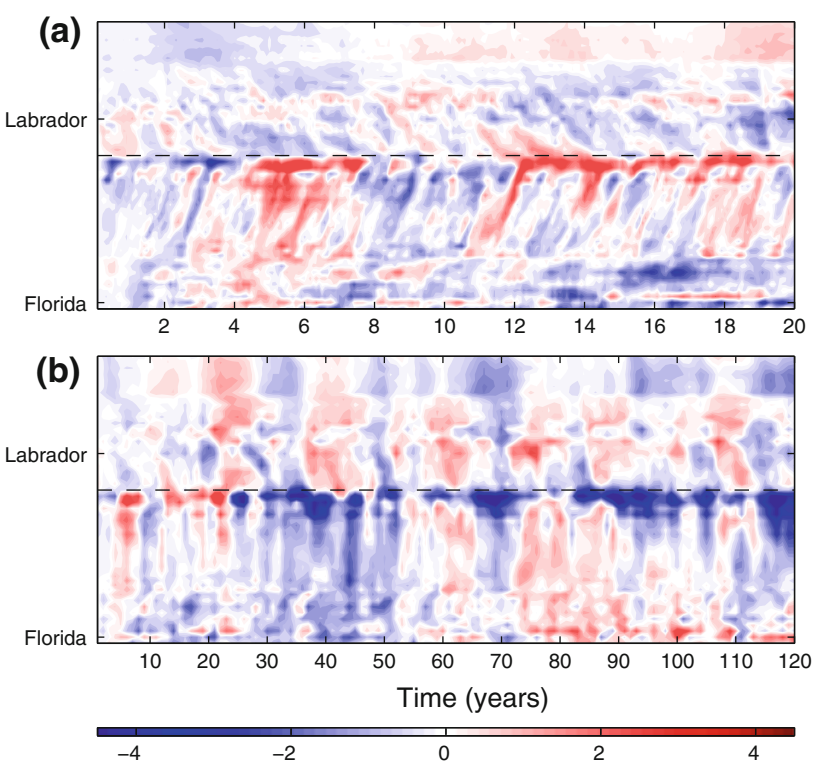

Fig. 5 Salt content anomalies for a 3 grid-box wide path along the western boundary of the North Atlantic basin, from $28-75^{\circ} \mathrm{N}$ $\left(\mathrm{EXP}^{-}\right.$- control $)\left[10^{12} \mathrm{~kg}\right]$ : a monthly anomalies for the first 20 years; b annual anomalies for the 120 year simulation. The dashed line lies at $48^{\circ} \mathrm{N}$, indicating the partition between the subpolar and sub-tropical gyres

rapidly as it is advected with currents and enters mixed layers in the upper levels of the ocean. However, the portion of the anomaly that lies at intermediate depths (500-1,500 m) spreads and remains at these depths. After 30 years, a region of significant freshening can be seen between $40-50^{\circ} \mathrm{N}$. This anomaly is seen at the surface and penetrates to at least $2,000 \mathrm{~m}$, indicating that cooler, fresher water may be surfacing in this region. At this latitude, in the NAC, the mixed layer depths are $>300 \mathrm{~m}$, allowing the intermediate waters to surface. After 50 years, the majority of the Atlantic is seen to be fresher between depths of 500-2,000 m. As the simulation continues, the fresher water builds up north of $60^{\circ} \mathrm{N}$ (Fig. 4). After 70 years (Fig. 6) there is a freshening in this region down to 3,000 $\mathrm{m}$ (level 16 in HadCM3). This is present throughout the water column as the fresher water sinks during formation of deep waters around the southern tip of Greenland. The impact of this freshening in the north is discussed in Sect. 3.2. As the fresh anomaly spreads southwards in the deep waters, the mean salt content in the Atlantic decreases in the deep levels (14-20) and increases in the layers above (not shown). By the end of the simulation there is still a significant reduction in salt content at intermediate depths in the Atlantic of $3.48 \times 10^{14} \mathrm{~kg}$, equivalent to $28 \%$ of the original perturbation. Along with this, a heat reduction of $4.30 \times 10^{21} \mathrm{~J}$ still remains in the intermediate depths between $30^{\circ} \mathrm{S}$ and $70^{\circ} \mathrm{N}$, equivalent to $17 \%$ of the initial perturbation. 

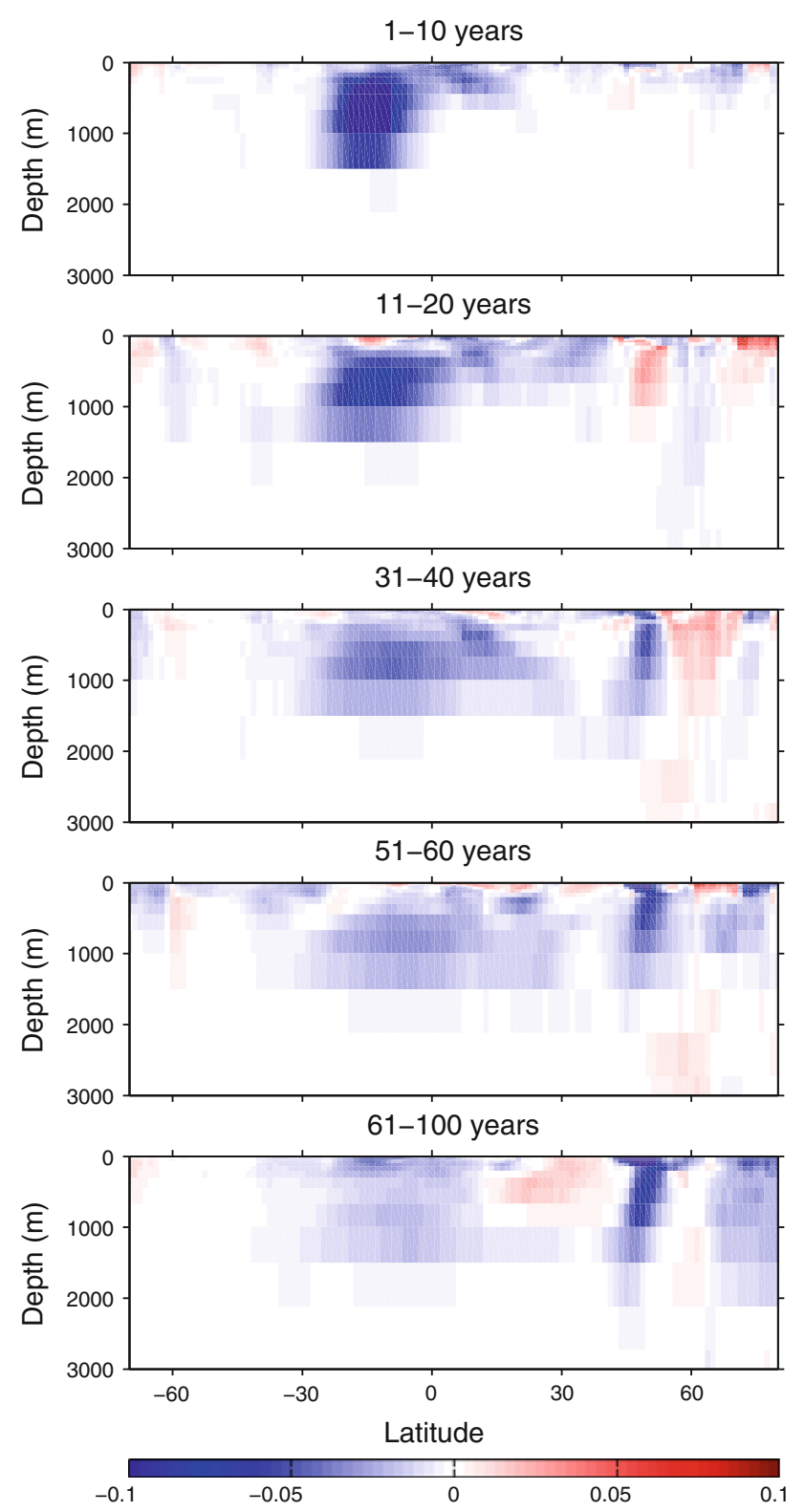

Fig. 6 Zonal average salinity anomalies $\left(\mathrm{EXP}^{-}-\mathrm{control}\right)$ in the Atlantic basin for 1-10, 11-20, 31-40, 51-60 and 61-100 years. For reference, control salinity contours can be seen in Fig. 3

\subsection{Changes seen at the sea surface and in the MOC}

In order for the changes in the ocean to have any influence on the atmosphere, they must be present at the surface. Although it has been shown that the changes in heat and salt content remain mostly below $300 \mathrm{~m}$ in the ocean, anomalies are seen at the surface (Fig. 7a, b). There is a significant cooling in the surface of the North Atlantic during the second half of the simulation. The signs of the heat flux anomalies (Fig. 7c, d) show that changes at the surface are driven by the ocean rather than the atmosphere, as regions with a cooler SST have positive heat flux anomalies, absorbing more heat from the atmosphere, rather than losing it. There is a cooling seen in the NAC region within the first 50 years. The significant anomaly develops after 30 years and grows as the simulation progresses, with a reduction of up to $1^{\circ} \mathrm{C}$ in the later decades.

Previous studies using HadCM3 have shown that low frequency SST variability in the North Atlantic (over multidecadal timescales) is primarily driven by changes in the Atlantic meridional overturning circulation (MOC), resulting in changes in the meridional heat transport (Vellinga and $\mathrm{Wu}$ 2004; Knight et al. 2005). Figure 8 shows the timeseries of the MOC indices for the Atlantic. These are taken to be the maximum overturning streamfunction at specific latitudes. The latitudes shown here are $26.25^{\circ} \mathrm{N}, 45^{\circ} \mathrm{N}$ and $60^{\circ} \mathrm{N}$, the approximate latitudes of the RAPID array (Cunningham et al. 2007), maximum overturning strength and maximum MOC anomalies, respectively. The MOC strength initially shows an increase, followed by a significant reduction, corresponding to the decreased SST. The reduction develops first at $60^{\circ} \mathrm{N}$, with the mean index showing negative anomalies at 31-40 years. This decrease then propagates southwards, at $45^{\circ} \mathrm{N}$ for $41-50$ years, and at $26.25^{\circ} \mathrm{N}$ for $61-70$ years. The largest anomalies are seen at $81-90$ years, with anomalies of $-0.8,-0.6$ and $-0.4 S v$ at 60,45 and $26.25^{\circ} \mathrm{N}$, respectively. At 45 and $60^{\circ} \mathrm{N}$, the reduction after 50 years is significant at the $95 \%$ confidence level, and all ensemble members show negative anomalies for 91-100 years. After 100 years the MOC strength begins to recover, although by the end of the integration, at 111-120 years, there is still a reduced strength, with a maximum value at $45^{\circ} \mathrm{N}$ of 17.4 Sv in the mean of the perturbed runs, compared with $17.8 \mathrm{~Sv}$ in the mean of the control simulations.

Thorpe et al. (2001) show that on decadal timescales the strength of the Atlantic MOC in HadCM3 is correlated with the steric height gradient in the Atlantic, between $30^{\circ} \mathrm{S}-60^{\circ} \mathrm{N}$. The steric height is given by

$-\int_{H}^{0} \frac{\delta \rho}{\rho_{0}} d z$,

where $\rho_{0}$ is a constant reference potential density and $\delta \rho$ is the density anomaly (EXP ${ }^{-}$- Control). Following Thorpe et al. (2001), we take $\mathrm{H}$ to be $3,000 \mathrm{~m}$, equivalent to level 16 in the model. Positive anomalies indicate a greater steric height difference between $30^{\circ} \mathrm{S}$ and $60^{\circ} \mathrm{N}$ in the perturbation experiment, and vice versa. These anomalies have a positive correlation of 0.68 with the MOC strength anomalies at $45^{\circ} \mathrm{N}$ (Fig. 8b). This relationship is driven primarily by the steric height at $60^{\circ} \mathrm{N}$, as there is relatively little change in density in the South Atlantic. This is illustrated in Fig. 9, which shows the steric height anomaly at each grid point for years 81-90. Positive anomalies in 
Fig. 7 50-year-average anomalies (EXP-control) for first 100 years of: $\mathbf{a}, \mathbf{b}$ sea surface temperature (SST) for $\operatorname{EXP}^{-}\left[{ }^{\circ} \mathrm{C}\right] ; \mathbf{c}, \mathbf{d}$ total heat flux in the atmosphere-ocean direction for $\mathrm{EXP}^{-}\left[\mathrm{W} \mathrm{m}^{-2}\right]$; e, f SST for $\mathrm{EXP}^{+}\left[{ }^{\circ} \mathrm{C}\right]$. Black contours indicate anomalies significant at the $95 \%$ confidence level

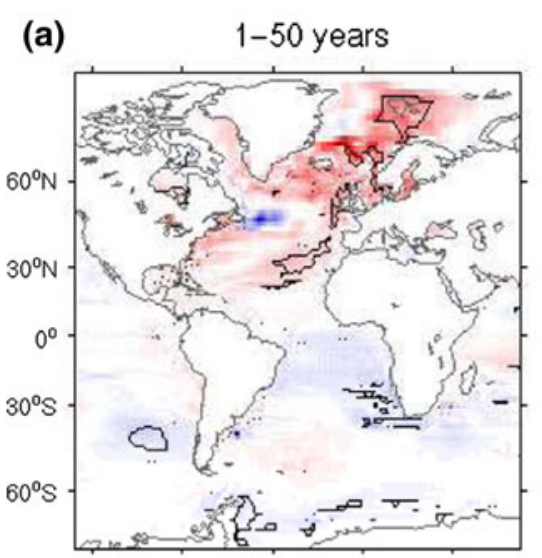

(c)

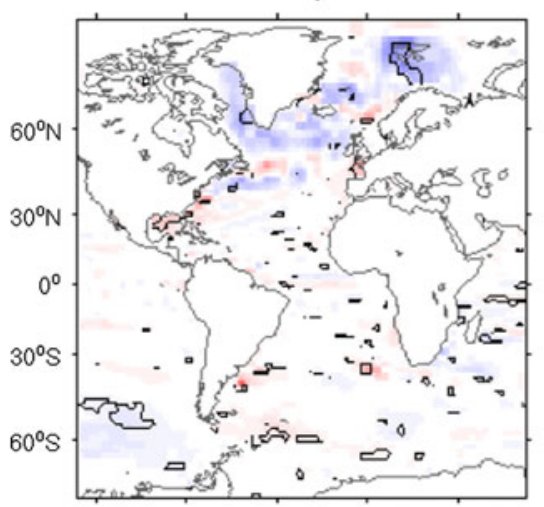

(e)

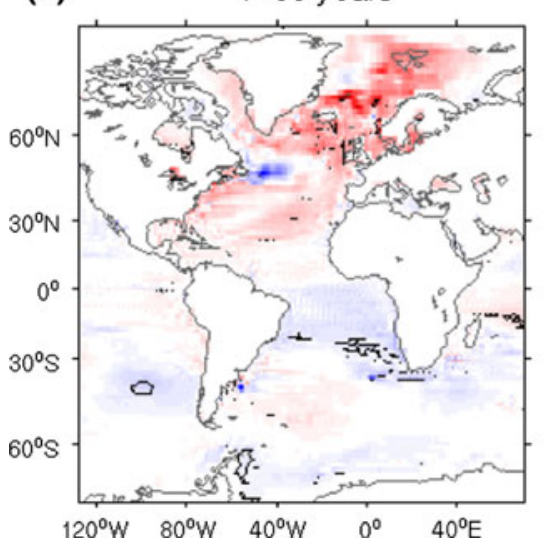

(b)

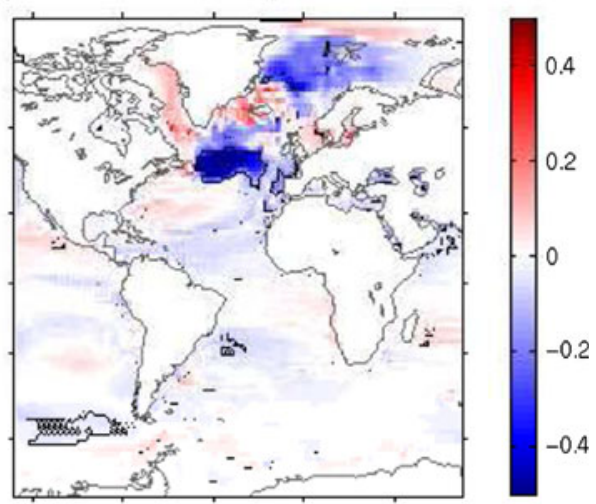

(d)

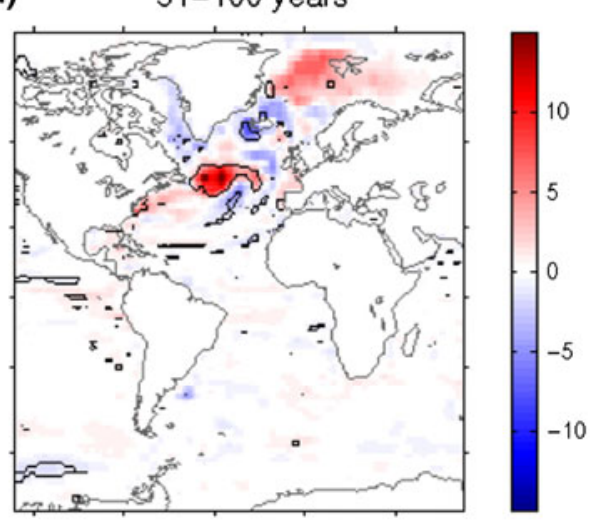

(f)

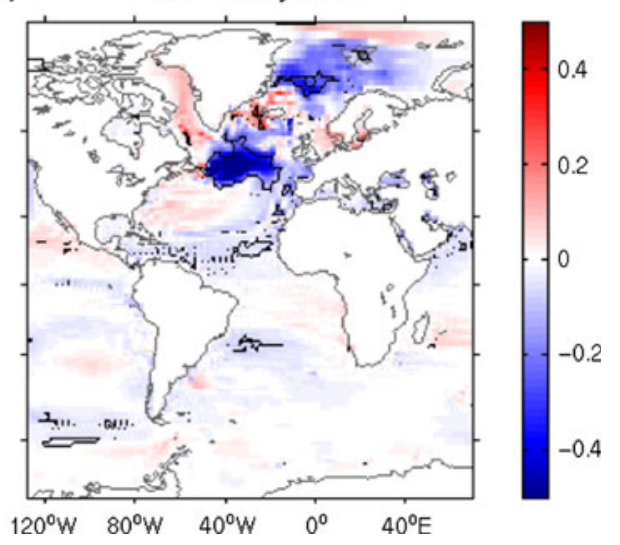

the steric height indicate a decrease in density in the water column. Around the tip of Greenland and in the GIN Seas, there is an overall increase in steric height and decrease in density compared with the control ensemble. Although there is also an increased steric height in the South Atlantic, this is smaller than that in the north. The control climate has a negative steric height gradient. Therefore, the resulting difference $\left(30^{\circ} \mathrm{S}-60^{\circ} \mathrm{N}\right)$ is reduced during the course of this experiment, compared with the control ensemble.
The reduction in overturning strength is therefore driven by decreasing density at $60^{\circ} \mathrm{N}$. Such a change could be caused by either a warming or freshening at this latitude. Figure 10a shows the total zonal heat content anomalies in the Atlantic. The initial cool anomaly advects northwards through the North Atlantic, as described earlier. Within 30 years, the cool anomaly reaches the NAC $\left(\sim 45^{\circ} \mathrm{N}\right)$. It takes a further 30 years before it builds up further north, 60 years into the simulation. As the water moves through the NAC and into the Greenland Sea, it cools the 

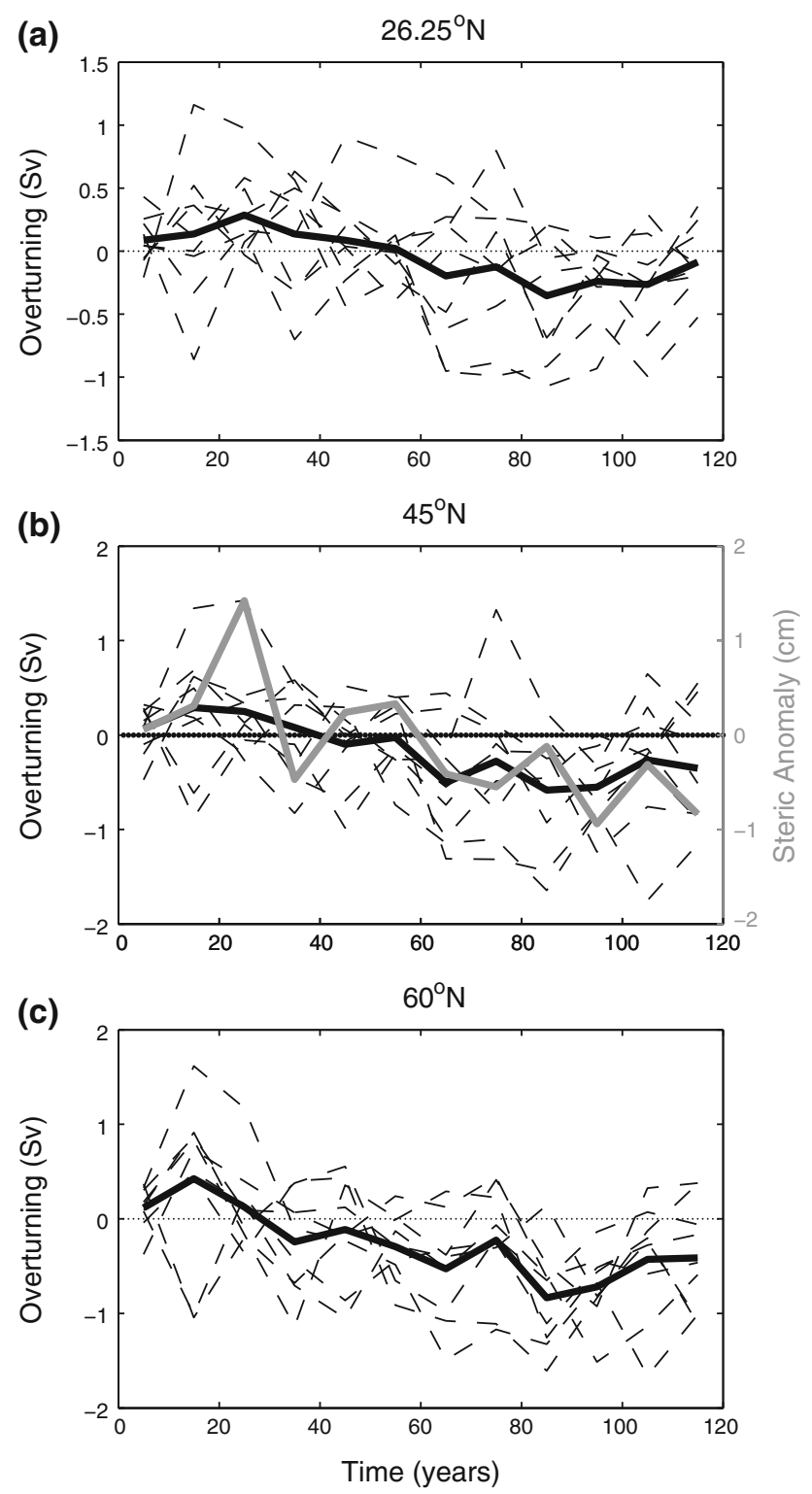

Fig. 8 Decadal average MOC strength anomalies (black) within the Atlantic at a $26.25^{\circ} \mathrm{N}, \mathbf{b} 45^{\circ} \mathrm{N}$ and c $60^{\circ} \mathrm{N}$. Panel b also shows the steric height difference anomalies, $30^{\circ} \mathrm{S}-60^{\circ} \mathrm{N}$ within the Atlantic (gray). Solid lines indicate the anomaly of ensemble mean values (EXP ${ }^{-}$- Control); dashed lines show the anomalies of individual $\mathrm{EXP}^{-}$ensemble members minus mean of the control

atmosphere above it (Fig. 7d). This process of the surface ocean absorbing heat from the atmosphere leaves a warmer, fresher and hence less dense water mass. The effects can be seen in Fig. 10b, as the decrease in density leads to an increase in steric height around $60^{\circ} \mathrm{N}$ and further north after 60 years. The strongest reduction in the MOC, at years $81-90$, occurs after the arrival of the fresher water moving southward. The timescale for the anomalies to propagate northwards is consistent with those seen in previous experiments. For example, in HadCM3, tracer released at the surface in the tropical North Atlantic took 5

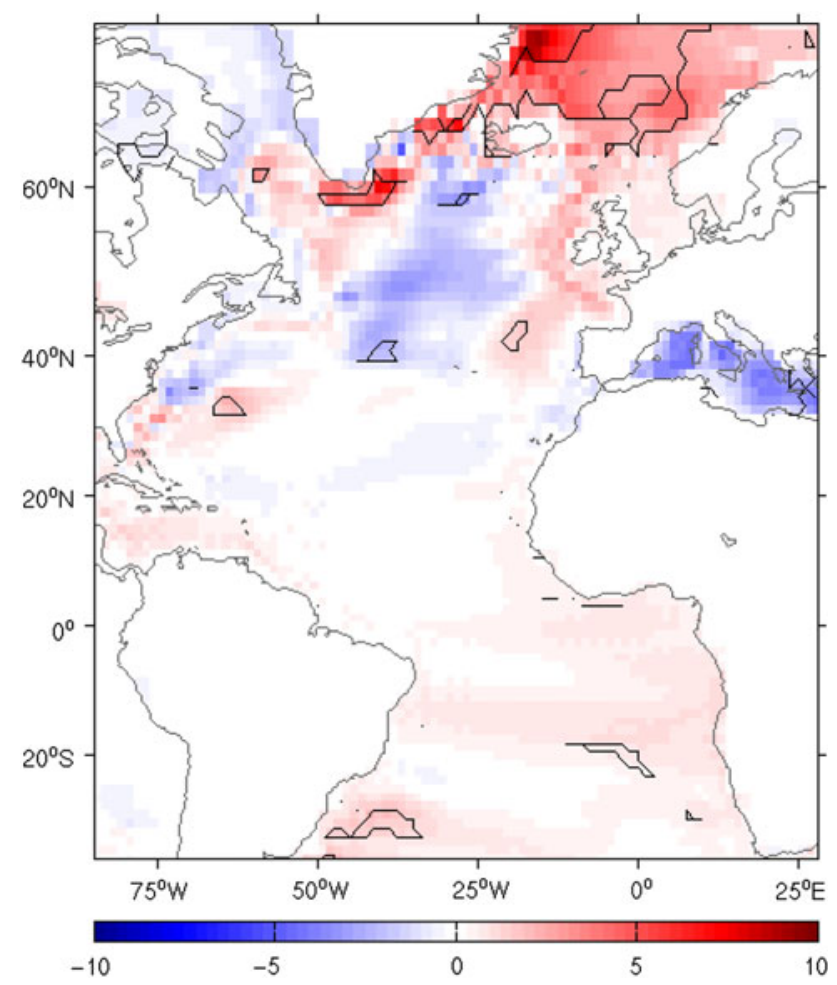

Fig. 9 Decadal average steric height anomalies (EXP ${ }^{-}-$Control), integrated to $3,000 \mathrm{~m}$ within each column [cm] for $81-90$ years. Increase in steric height is equivalent to a decrease in density within the column. Black contours indicate anomalies significant at the $95 \%$ confidence level

to 6 decades to build to significant concentrations in the GIN Seas, due to the processes of dispersion and recirculation that occur along with the northward advection (Vellinga and Wu 2004). Sen Gupta and England (2007) performed tracer release experiments in AAIW formation regions using a $1 / 4^{\circ}$ resolution model. Tracer released at the surface in the southeast Indian Ocean was found to reach $1 \%$ concentration at $60^{\circ} \mathrm{N}$ in the Atlantic within 60 years on $\sigma_{0}>27.0, \sim 40$ years after reaching our perturbation region. They also show that the ventilation timescale for AAIW in the Atlantic ranges from 50-150 years, consistent with observations (Holzer et al. 2010).

The strongest SST anomalies, which develop around the NAC, persist from 30 years through to the end of simulation (Fig. 11a). The cool, fresh anomaly extends down from the surface to $>2,000 \mathrm{~m}$ (Fig. 6), indicating that anomalous water is surfacing in this region. Further analysis of this anomaly shows that there is a divergence of meridional ocean heat fluxes from this region (bounded by $45^{\circ} \mathrm{N}$ and $53^{\circ} \mathrm{N}$ ), with increased heat transport leaving to the north, as well as a reduction of heat arriving from the south (Fig. 11c). From the south, a combination of cooler AAIW being carried northwards and the reduction in the 
Fig. 10 Hovmöller plots of: heat content anomalies (EXPControl), within 0-3,000 m $\left[10^{21} \mathrm{~J}\right]$ for a $\mathrm{EXP}^{-}$and c $\mathrm{EXP}^{+}$; zonal mean steric height anomalies (EXPControl) $[\mathrm{cm}]$ for $\mathbf{b} \mathrm{EXP}^{-}$and d $\mathrm{EXP}^{+}$
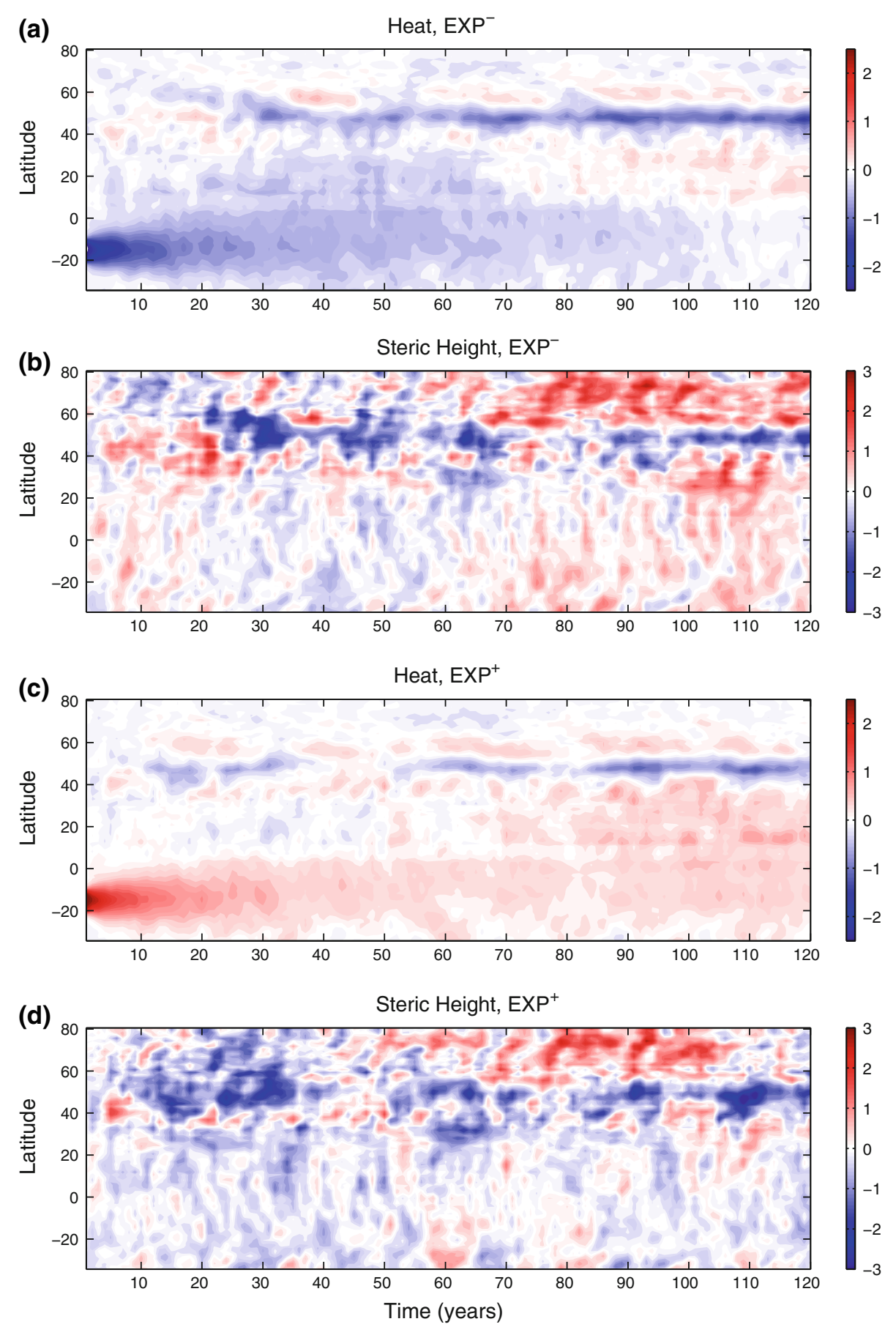

MOC strength can both account for the reduced heat transport. To the northern side of the region, the increased heat transport may be accounted for by an increased volume of cool water moving southward from $>53^{\circ} \mathrm{N}$. Hátún et al. (2005) show that during periods of increased gyre transport, water from the SPG constitutes a larger proportion of that in the NAC, compared with water from the subtropical gyre (STG). During the simulation, there is an increased transport in the SPG (not shown), although it is important to note that there is no change in the southern limit of the gyre. The increased gyre transport seen in this experiment may then lead to increased transport of cool, fresh water southward from the Labrador Sea. The southward transport of anomalous water can be seen in Figs. 5 and $10 \mathrm{a}$, in particular during $20-30$ and $70-80$ years. The link between this southward transport for years 20-30 and the initial increased MOC strength is discussed in Sect. 5. The atmospheric response to this persistent anomaly is presented in Sect. 3.3. 
Fig. 11 Heat anomalies in the region of the North Atlantic Current: average SST anomaly between 45 and $53^{\circ} \mathrm{N}$ in the Atlantic for a $\mathrm{EXP}^{-}$, $\mathbf{b} \mathrm{EXP}^{+}$; meridional ocean heat flux anomaly $\left(53^{\circ} \mathrm{N}-45^{\circ} \mathrm{N}\right)$ for c $\mathrm{EXP}^{-}, \mathbf{d ~ E X P}^{+}$. Solid lines indicate the anomaly of ensemble mean values (EXPControl); dashed lines show the anomalies of individual ensemble members minus mean of the control; shaded areas show the $95 \%$ spread of the control ensemble. Values have been smoothed using a 5 year running mean

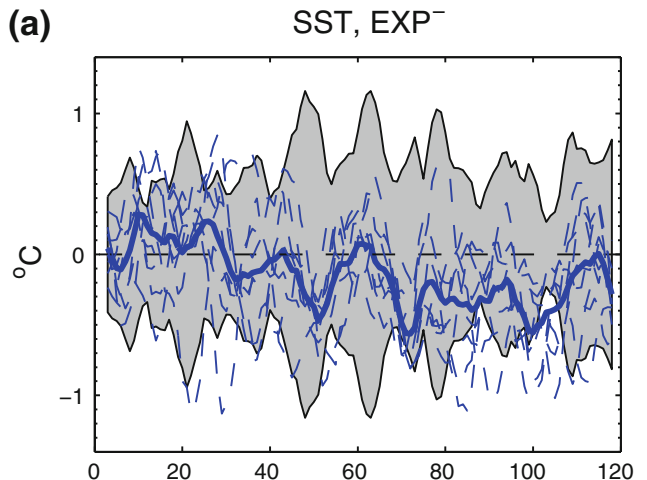

(b)

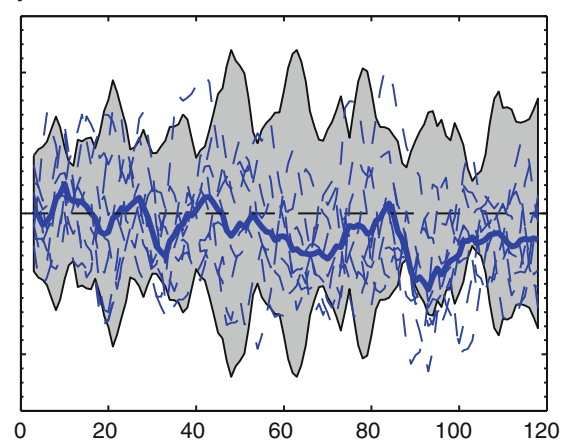

(c)

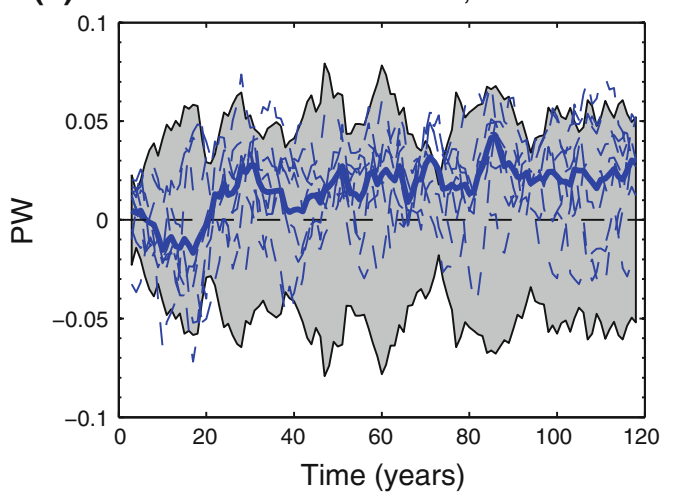

(d)

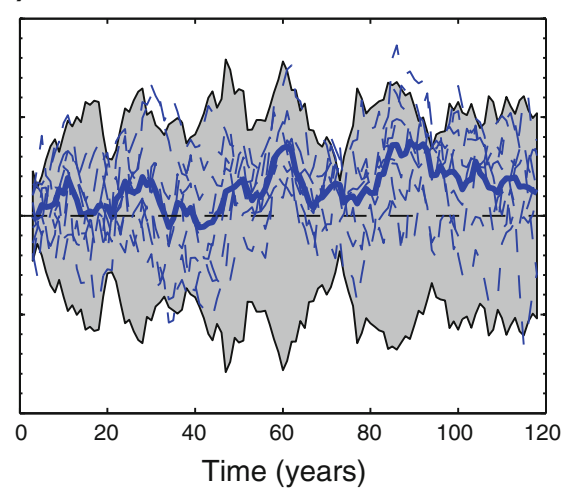

\subsection{Atmospheric responses to the anomaly}

The cooling of the North Atlantic seen in this experiment can have a series of atmospheric responses. The presence of the cooler SSTs leads to a cooling of the overlying atmosphere, and hence we expect to see cooler surface air temperatures (SATs) over the ocean and its surrounding continents. The maximum anomalies in the global surface atmospheric temperature occur for years 61-70 (not shown). There is a mean global SAT anomaly of $-0.07^{\circ} \mathrm{C}$ for this decade. For years $51-100$ there is an atmospheric cooling over the areas of cooler SSTs (Fig. 12a). Anomalies are particularly large over the GIN Seas, and significant around $45^{\circ} \mathrm{N}$ in the North Atlantic. As well as leading to a reduction in SAT, the cooler surface waters also have a significant impact on precipitation and mean sea level pressure (MSLP) (Fig. 12b, c). Little change is seen over the surrounding continents, although there is significant cooling over the Middle East (Fig. 12a).

Previous studies of the atmospheric response to the basin-wide shifts in Atlantic SST, known as the Atlantic Multidecadal Oscillation (Delworth and Mann 2000), have shown responses in the rainfall patterns across the southern US and Sahel region of Africa (Sutton and Hodson 2005). The average precipitation for years 51-100 (Fig. 12b) shows that there is little significance in the precipitation changes. However one of the areas that does show a significant decrease is northwest Africa and southwest Europe. In this region, there is a decrease of up to $3.0 \mathrm{~cm} /$ year for years $51-100$ (5\% of the average). Sutton and Hodson (2005) show that the response to the Atlantic Multidecadal Oscillation (AMO) in the Sahel is weaker in the atmospheric component of HadCM3 (HadAM3) than in observations, likely as a result of land surface feedbacks that are not included in the model. The response over this region may then be underestimated in this study.

The response over the USA is weaker than that usually associated with the AMO (Sutton and Hodson 2005), with no regions of significance and precipitation increases of only up to $2.4 \mathrm{~cm} \mathrm{year}^{-1}$ (Fig. 12b). This weak response in the precipitation field is associated with a weak MSLP response over the USA (Fig. 12c). Sutton and Hodson (2005) show that the warm phase of the AMO leads to lower pressure over the southern US, and a decrease in rainfall. A cool phase should then lead to the opposite effect. However, although the majority of the North Atlantic is cooler for years $51-100$, the cooling mostly occurs north of $40^{\circ} \mathrm{N}$, in the extratropics. There is also a weak tripole effect with positive anomalies off the east coast of North America (Fig. 7b). As the response over North America is predominantly driven by the SST anomalies in the tropical North Atlantic, $0-30^{\circ} \mathrm{N}$ (Sutton and Hodson 2005), this accounts for the weaker atmospheric response seen in these results. The precipitation 
Fig. 12 Mean atmospheric anomalies for 51-100 years (EXP ${ }^{-}$- Control): a surface air temperature (SAT) $\left[{ }^{\circ} \mathrm{C}\right]$; b precipitation $\left[\mathrm{cm}\right.$ year $\left.{ }^{-1}\right]$; c mean sea level pressure (MSLP) [Pa]; d zonal wind speed $\left[\mathrm{m} \mathrm{s}^{-1}\right]$. Black contours show anomalies significant at the $95 \%$ confidence level
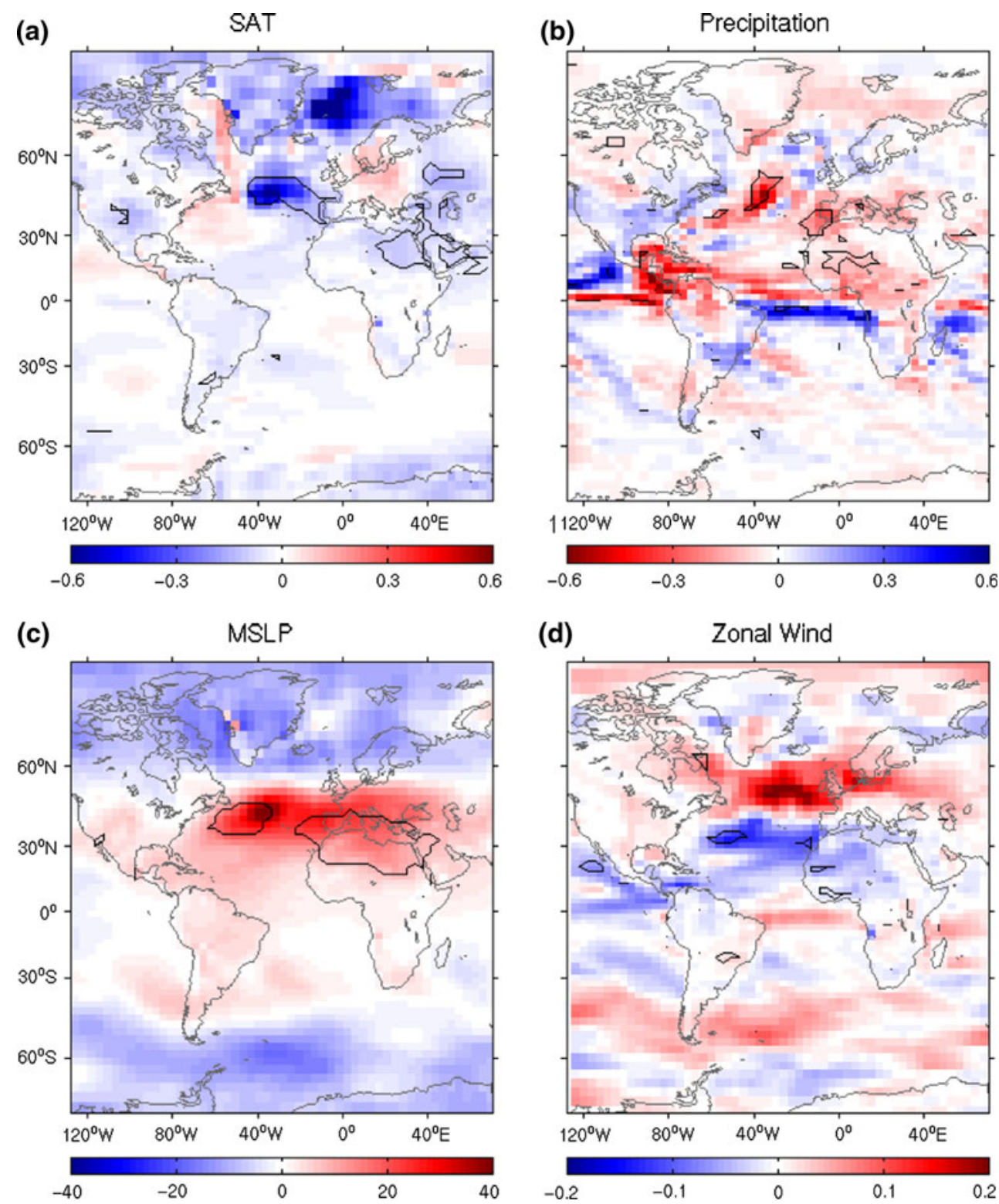

(d)

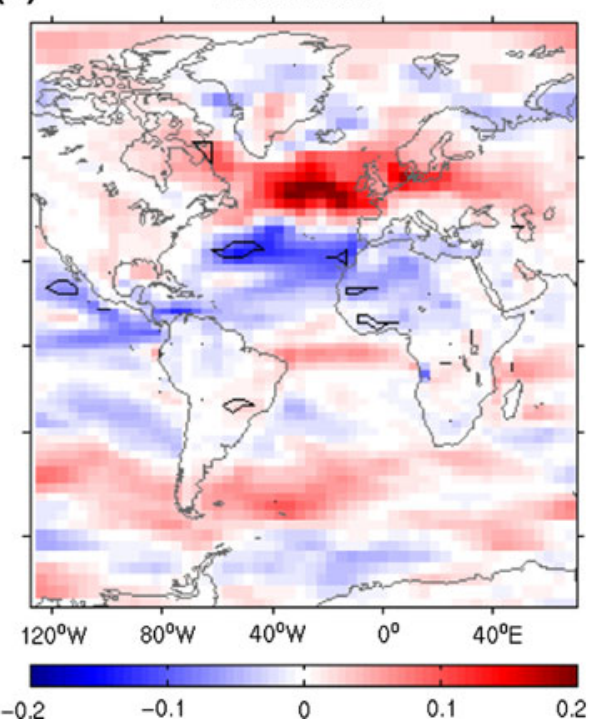

anomalies seen within the tropics are characteristic of a shift in the Intertropical Convergence Zone (ITCZ), which has been shown to occur with changes in the strength of the MOC (Vellinga and Wu 2004).

Tripole patterns in the North Atlantic are characteristic of the North Atlantic Oscillation (NAO) (Deser and Blackmon 1993; Seager et al. 2000). The higher MSLP over $15-45^{\circ} \mathrm{N}$ (Fig. 12c) is associated with positive phases of the NAO, with stronger westerlies over the North Atlantic storm track (Fig. 12d). As mentioned in Sect. 3.2, the SPG may account for the increased gyre transport contributing to the divergence of heat transport observed in the NAC (Fig. 11c). Increased wind stress curl is observed over the SPG for years 21-30 and 71-80 (not shown), when increased transport of cold water can be seen moving southwards from $>53^{\circ} \mathrm{N}$ in Fig. 10a. A feedback mechanism may then contribute to the persistence of the cold anomaly in this region, where the SST anomalies lead to MSLP and wind anomalies that act to increase the transport in the SPG. This in turn increases the proportion of cooler water in the NAC.

\section{Response to a warm, saline anomaly}

The second perturbation experiment investigated the impact of a warmer, saltier AAIW. As with $\mathrm{EXP}^{-}$, anomalies are advected northward in the Atlantic along the western boundary. From here, a portion of the perturbed water mass is carried further north and significant increases in heat and salt content are found in the SPG, around $60^{\circ} \mathrm{N}$, by years 21-30 (Fig. 10c). The remainder of the water 
mass gradually fills the North Atlantic as it recirculates with the subtropical gyre. Figure 10c shows that there is an increased heat content throughout the majority of the Atlantic basin by the end of the simulation. After 120 years, a heat anomaly of $6.52 \times 10^{21} \mathrm{~J}$ and a salt anomaly of $4.64 \times 10^{14} \mathrm{~kg}$ remain at intermediate depths in the Atlantic. This corresponds to 27.0 and $36.8 \%$ of the initial anomalies respectively. Increased heat content at $60^{\circ} \mathrm{N}$ leads to an increase in the steric height anomalies (Fig. 10d) that drive a resulting decrease in the MOC through the simulation. The maximum decrease occurs during years 81-90, with reductions of $0.4,0.6$ and $0.7 \mathrm{~Sv}$ for $26.25,45$ and $60^{\circ} \mathrm{N}$ respectively (not shown). After this the MOC begins to recover, and by the end of the simulation positive anomalies are present at each of these three latitudes, with a mean maximum overturning strength of $18.0 \mathrm{~Sv}$ at $45^{\circ} \mathrm{N}$ for $\mathrm{EXP}^{+}$, compared with $17.8 \mathrm{~Sv}$ for the control ensemble.

Little significant response is seen in the time-mean SST for the first 50 years of the simulation (Fig. 7e). However, the SST anomalies in the SPG are accompanied by significant heat and salt content increases through the water column. This suggests that the warmer, saltier water is surfacing in these regions of increased MLD $(>300 \mathrm{~m})$. For years 51-100, the reduction in ocean heat transport, due to the decrease in the MOC strength through the course of the simulation, results in a surface cooling in the North Atlantic (Fig. 7f). The surface cooling is particularly strong in the region of the NAC and the GIN Seas. The cooling in the NAC region begins after 50 years and persists for the remainder of the simulation (Fig. 11b). As with $\mathrm{EXP}^{-}$, this cold anomaly can be attributed to a divergence of heat transport from the region (Fig. 11d). The reduced MOC strength leads to a decrease in meridional heat transport from the south. Increased SPG transport brings cooler, fresher water from the north. The strongest surface cooling is found for years 91-100. This follows the decade of the strongest MOC anomalies, and during this time there is a significant increase in the SPG transport (not shown). However, it should be noted that the cooling in this region is not as strong as that seen for $\mathrm{EXP}^{-}$. This is likely a result of the smaller decrease in the northward heat transport from the south due to the presence of warmer intermediate waters.

Figure 13 shows the atmospheric response to the SST anomalies during years $51-100$ of $\mathrm{EXP}^{+}$. Surface fluxes show that the SAT anomalies are predominantly driven by the underlying ocean, with significant cooling in particular around the region of the NAC and GIN seas (Fig. 13a). Significant cooling is also seen over the Middle East and North America. The precipitation, MSLP and zonal wind anomalies are less significant than those for $\mathrm{EXP}^{-}$ (Fig. 13b-d). This is likely a result of the warm surface anomalies found around Iceland and in the Labrador sea (Fig. 7f). The precipitation and MSLP responses to North Atlantic SST described by Sutton and Hodson (2005) show that the effects over Europe and Africa are due to the cooling in the subtropical Atlantic $\left(>30^{\circ} \mathrm{N}\right)$. As the cooling over the NAC region is not as strong as that in $\mathrm{EXP}^{-}$, and there is a warming north of this region, this may account for the smaller atmospheric anomalies in these regions. The weak response in the MSLP, can also account for the smaller zonal wind anomalies (Fig. 13d). Although the atmospheric response is weaker than that seen in $\mathrm{EXP}^{+}$, the MSLP and zonal wind anomalies may contribute to the persistence of the cool anomaly in the NAC, through the same mechanism described in Sect. 3.3.

\section{Discussion and conclusions}

This study has investigated the potential climate impacts of changes in AAIW. For the first experiment $\left(\mathrm{EXP}^{-}\right)$, AAIW was perturbed between 10 and $20^{\circ} \mathrm{S}$ in the Atlantic, decreasing the temperature by $1{ }^{\circ} \mathrm{C}$ and making a corresponding decrease in salinity to maintain a constant density. After 50 years, a decrease in SST is seen in the North Atlantic. This is primarily due to the cooler, fresher water mass surfacing in regions of deeper mixed layer depth (MLD), in particular around the NAC. As the fresher water builds up further north, a reduction in the density through the water column then leads to a reduced overturning strength.The MOC strength in the Atlantic is shown to be positively correlated with the steric height difference between $30^{\circ} \mathrm{S}$ and $60^{\circ} \mathrm{N}$, with the density variations at $60^{\circ} \mathrm{N}$ being the key factor. The largest MOC anomalies were found at $60^{\circ} \mathrm{N}$ for $81-90$ years, with a decrease of $0.8 \mathrm{~Sv}$ over the decade. While the anomalies presented here are smaller than the detection limit of the RAPID array $(1.5 \mathrm{~Sv})$, these limits are in the context of interannual variability (Cunningham et al. 2007). Here we are discussing decadal-mean anomalies, over centennial timescales. Also, the aim of this paper is not to make a prediction of the magnitude of future changes, but rather to understand the processes that may be involved.

In the initial stages of the $\mathrm{EXP}^{-}$simulation, up to year 30, there is an increased SST in the North Atlantic, along with an increased MOC strength. This increase appears to be a result of MSLP anomalies over Greenland and the GIN Seas. For years 11-30 there is a reduction in the MSLP in this region compared with the control ensemble, resulting in an increased wind strength moving southwards over the Labrador Sea. The increased MLD that results from this will lead to increased production of Labrador Sea Water (Cooper and Gordon 2002), which can be seen as the cooler water moving southwards in Fig. 10 , from $>60^{\circ} \mathrm{N}$ to 
Fig. 13 Mean atmospheric anomalies for 51-100 years $\left(\mathrm{EXP}^{+}\right.$- Control): a surface air temperature (SAT) $\left[{ }^{\circ} \mathrm{C}\right]$; b precipitation $\left[\mathrm{cm}\right.$ year $\left.{ }^{-1}\right]$; c mean sea level pressure (MSLP) [Pa]; d zonal wind speed $\left[\mathrm{m} \mathrm{s}^{-1}\right]$. Black contours show anomalies significant at the $95 \%$ confidence level
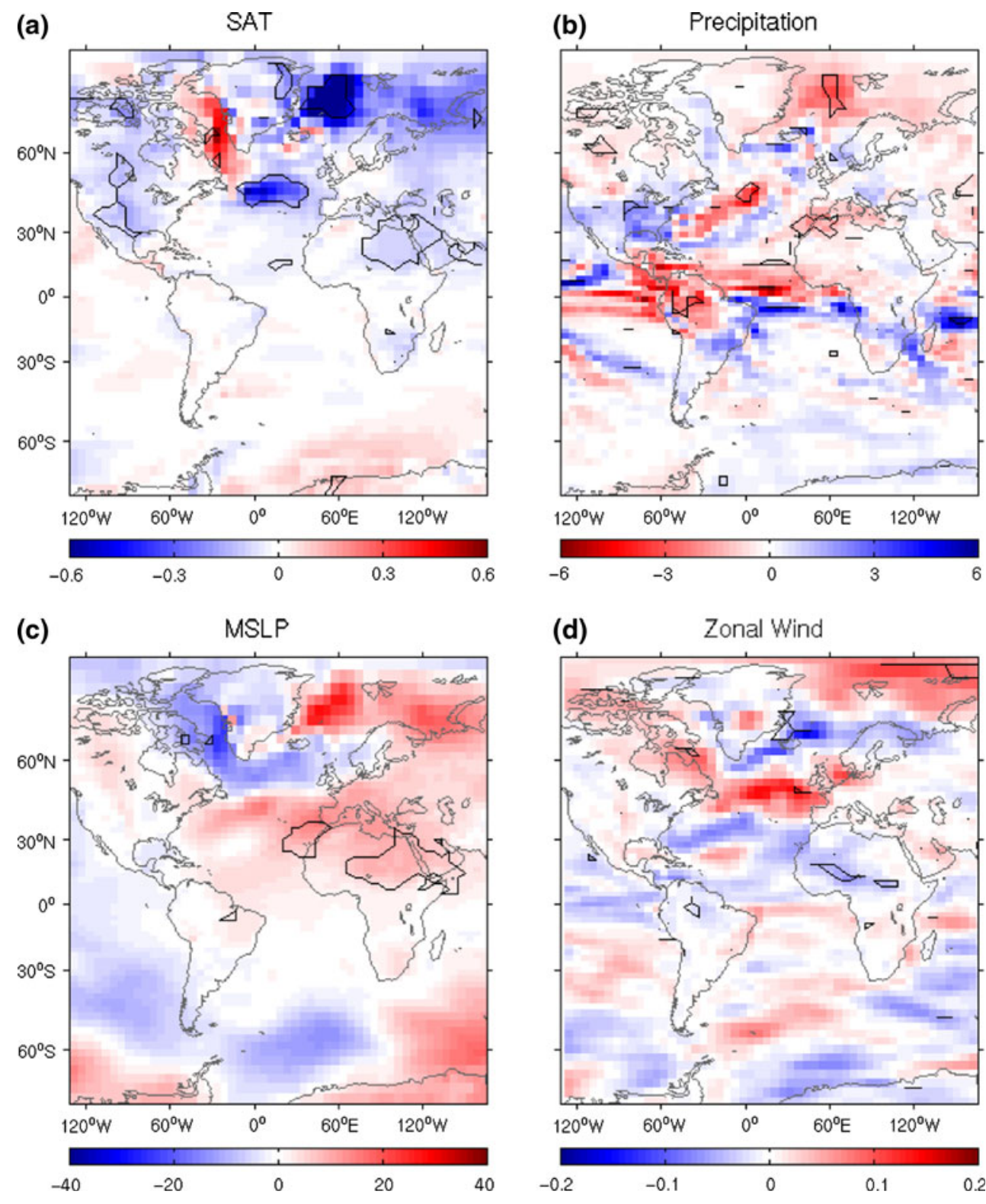

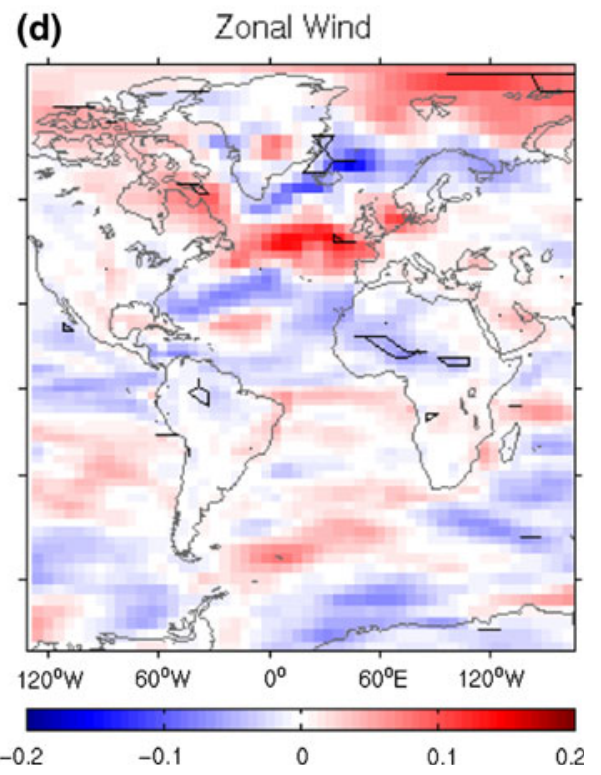

the NAC, during years 10-30. This decreased heat content leads to an increased density and hence a decrease in steric height. Whilst this increase in the MOC is significant for years $21-30$, the mean changes in MSLP lie within the range of internal variability and are less significant than the MOC anomalies. This suggests that the initial increase in MOC strength may be due to internal variability in the model, rather than a direct result of our perturbation. This is supported by the fact that there is little significance in the heat flux anomalies between the ocean and atmosphere for the first 20 years. As the ensemble size was increased, the statistical significance of this initial warming was found to decrease, however the cooling and decreased MOC strength in the second half of the simulation remained significant at the $95 \%$ level, giving greater confidence in this result.

The persistent cold surface anomaly in the region of the $\mathrm{NAC}$ is found to result from a divergence of ocean heat transport between 45 and $53^{\circ} \mathrm{N}$. From the south, there is a reduced northward heat transport as the MOC strength decreases and the cooler intermediate water arrives. The increased heat transport to the north can be accounted for by the increased transport in the SPG. Increased volumes of cooler water are brought into the region, leading to a higher proportion of SPG water, compared with STG water, in the NAC (Hátún et al. 2005). Higher MSLP over the mid-latitude Atlantic, and corresponding zonal wind anomalies, lead to an increased wind stress curl that acts to strengthen 

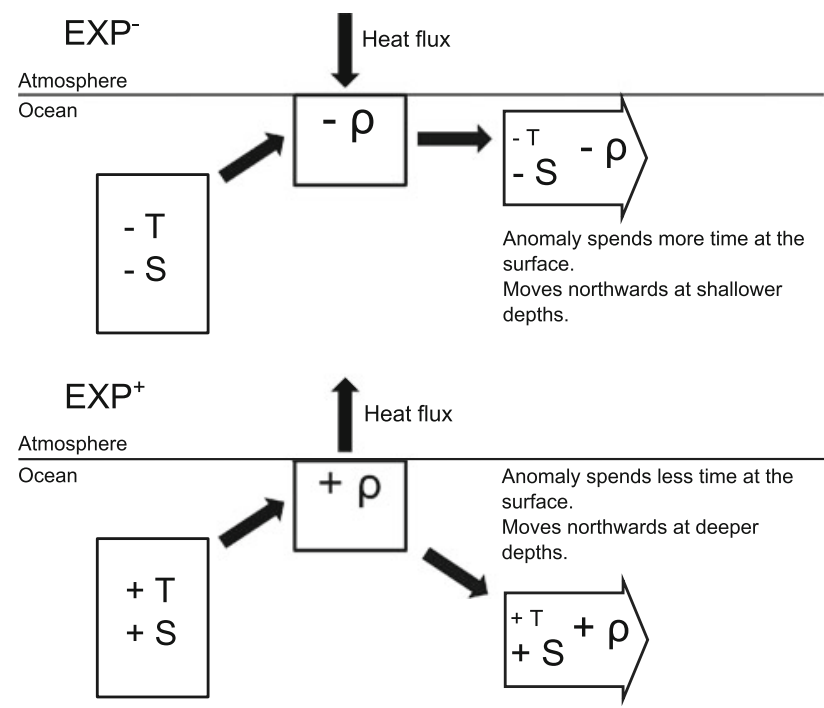

Fig. 14 Schematic to demonstrate the non-linear response to initially density-compensating perturbations. When the anomalous water mass comes in to contact with the atmosphere, heat fluxes result in opposite density anomalies due to the remaining salinity perturbation. Nonlinearity arises as the density anomalies propagate through the ocean at different depths and pathways

the gyre. As these MSLP anomalies develop over the cool NAC region, this may then lead to the persistence of the SST anomaly through a feedback mechanism.

A second perturbation experiment has been undertaken with a warmer, saltier AAIW (again for 120 years, with 9 ensemble members). The response seen was not equal and opposite to the response in the cooler, fresher experiment, implying that the climate response to these perturbations is non-linear. There is no increase in the SST around the NAC and no significant increase in the MOC. The MOC actually exhibits an average reduction in strength over the course of the simulation, as was seen in $\mathrm{EXP}^{-}$. However the trend seen in $\mathrm{EXP}^{+}$is less significant, with positive anomalies shown by the end of the simulation. Although there are no positive SST anomalies in the NAC, $\mathrm{EXP}^{+}$shows significantly increased SST anomalies around the tip of Greenland, suggesting that there may be a surfacing of warmer, saltier water in this region.

The fact that the two experiments do not show equal and opposite responses is not entirely unexpected. As the perturbed water masses reach the ocean mixed layer and interact with the atmosphere, the loss (gain) of heat in the warming (cooling) experiment will lead to positive (negative) density anomalies. This can be seen in the simulations within the first 20 years (not shown). These opposing density responses then lead to the water masses travelling along different paths in the ocean, surfacing in different regions, and spending different lengths of time at the surface. This concept is illustrated by the schematic in Fig. 14. At the end of the simulations, $28 \%$ of the initial salt content anomaly remains at intermediate depths in the Atlantic for $\mathrm{EXP}^{-}$, compared with $36.8 \%$ for $\mathrm{EXP}^{+}$. This supports the suggestion that the perturbations travel along different paths in the ocean, with the warmer, saltier anomaly showing a tendency to remain at greater depth and have less interaction with the atmosphere.

Climate change scenarios show that there is likely to be a freshening of intermediate waters by the end of this century (Sen Gupta et al. 2009), due to a combination of warming and freshening in the surface formation regions (Stark et al. 2006). The surface cooling shown to result from the perturbed water masses in both $\mathrm{EXP}^{-}$and $\mathrm{EXP}^{+}$ may act to reduce the warming trend seen from increased $\mathrm{CO}_{2}$ concentrations in the atmosphere. However, the patterns of MSLP and precipitation anomalies show some similarities to those presented in the IPCC AR4 projections (Meehl et al. 2007), with increased pressure over the midlatitude Atlantic and decreased precipitation over the western Mediterranean region. The results presented here show that projected changes in AAIW in the Atlantic can have an impact on the global climate system, and may contribute towards the pattern of change over the mid-latitude Atlantic and Mediterranean region with increasing $\mathrm{CO}_{2}$. As discussed in Sect. 1, there are still conflicting trends observed in Atlantic AAIW. More attention must be given to properties of intermediate waters in order to know their range of internal variability, and detect any trends of change. Only then may we fully understand how our climate will change in the future.

Acknowledgments Funding has been provided by a $\mathrm{PhD}$ studentship for the UK Natural Environment Research Council. This work has also been supported by a CASE studentship with the British Antarctic Survey. The research presented in this paper was carried out on the High Performance Computing Cluster supported by the Research Computing Service at the University of East Anglia. We would like to thank Ian Stevens for his technical support in the initial stages of this project, and two anonymous reviewers for their useful comments.

\section{References}

Arbic B, Owens W (2001) Climatic warming of Atlantic intermediate waters. J Clim 14:4091-4108

Aoki S, Bindoff NL, Church JA (2005) Interdecadal water mass changes in the Southern Ocean between $30^{\circ} \mathrm{E}$ and $160^{\circ} \mathrm{E}$. Geophys Res Lett 32:1-5

Banks HT, Bindoff NL (2003) Comparison of observed temperature and salinity changes in the Indo-Pacific with results from the coupled climate model HadCM3: processes and mechanisms. J Clim 16:156-166

Bindoff NL, McDougall TJ (2000) Decadal changes along an Indian Ocean section at $32^{\circ} \mathrm{S}$ and their interpretation. J Phys Oceanogr 30:1207-1222

Bryden HL, McDonagh EL, King BA (2003) Changes in ocean water mass properties: oscillations or trends? Sci Agric 300: 2086-2088 
Collins M, Tett SFB, Cooper C (2001) The internal climate variability of HadCM3, a version of the Hadley Centre coupled model without flux adjustments. Clim Dyn 17:61-81

Cooper C, Gordon C (2002) North Atlantic oceanic decadal variability in the Hadley Centre coupled model. J Clim 15:45-72

Cunningham SA, Kanzow T, Rayner D, Baringer MO, Johns WE, Marotzke J, Longworth HR, Grant EM, Hirschi JJ-M, Beal LM, Meinen CS, Bryden HL (2007) Temporal variability of the Atlantic meridional overturning circulation at $26.5^{\circ} \mathrm{N}$. Science 317:935-938

Curry R, Dickson B, Yashayaev I (2003) A change in the freshwater balance of the Atlantic Ocean over the past four decades. Nature 426:826-829

Delworth T, Mann M (2000) Observed and simulated multidecadal variability in the Northern Hemisphere. Clim Dyn 16:661-676

Deser C, Blackmon M (1993) Surface climate variations over the North Atlantic Ocean during winter: 1900-1989. J Clim 6:1743-1753

Gordon C, Cooper C, Senior CA, Banks H, Gregory JM, Johns TC, Mitchell JFB, Wood RA (2000) The simulation of SST, sea ice extents and ocean heat transports in a version of the Hadley Centre coupled model without flux adjustments. Clim Dyn $16: 147-168$

Hátún H, Sandø AB, Drange H, Hansen B, Valdimarsson H (2005) Influence of the Atlantic subpolar gyre on the thermohaline circulation. Science 309:1841-1844

Holzer M, Primeau FW, Smethie WM Jr, Khatiwala S (2010) Where and how long ago was water in the western North Atlantic ventilated? Maximum entropy inversions of bottle data from WOCE line A20. J Geophys Res 115:1-26

Hughes T, Weaver A (1996) Sea surface temperature-evaporation feedback and the ocean's thermohaline circulation. J Phys Oceanogr 26:644-654

Knight JR, Allan RJ, Folland CK, Vellinga M, Mann ME (2005) A signature of persistent natural thermohaline circulation cycles in observed climate. Geophys Res Lett 32:4

Levitus S, Antonov JI, Boyer TP (2005) Warming of the world ocean. Geophys Res Lett 32:L02604

McCartney MS (1977) Subantarctic mode water. In: Angel M (ed) A voyage of discovery, supplement to deep-sea research, George Deacon 70th anniversary volume. Pergamon, New York, pp 103-119

Meehl GA, Stocker TF, Collins WD, Friedlingstein P, Gaye AT, Gregory JM, Kitoh A, Knutti R, Murphy JM, Noda A, Raper SCB, Watterson IG, Weaver AJ, Zhao Z-C (2007) Global climate projections. In: Solomon AM, Qin D, Manning M, Chen Z, Marquis M, Averyt KB, Tignor M, Miller HL (eds) Climate change 2007: The physical science basis. Contribution of
Working Group I to the Fourth Assessment Report of the Intergovernmental Panel on Climate Change. Cambridge University Press, Cambridge

Molinelli EJ (1981) The Antarctic influence on Antarctic Intermediate Water. J Mar Res 39:267-293

Pardaens AK, Banks HT, Gregory JM, Rowntree PR (2003) Freshwater transports in HadCM3. Clim Dyn 21:177-195

Piola AR, Gordon AL (1989) Intermediate waters in the southwest South Atlantic. Deep Sea Res 36:1-16

Saenko OA, Weaver AJ, Gregory JM (2003) On the link between the two modes of the ocean thermohaline circulation and the formation of global-scale water masses. J Clim 16:2797-2801

Seager R, Kushnir Y, Visbeck M, Naik N, Miller J, Krahmann G, Cullen H (2000) Causes of Atlantic Ocean climate variability between 1958 and 1998. J Clim 13:2845-2862

Sen Gupta A, England MH (2007) Evaluation of interior circulation in a high-resolution global ocean model. Part II: southern hemisphere intermediate, mode, and thermocline waters. J Phys Oceanogr 37:2612-2636

Sen Gupta A, Santoso A, Taschetto AS, Ummenhofer CC, Trevena J, England MH (2009) Projected changes to the southern hemisphere ocean and sea ice in the IPCC AR4 climate models. J Clim 22:3047-3078

Sijp WP, England MH (2008) The effect of a northward shift in the southern hemisphere westerlies on the global ocean. Prog Oceanogr 79:1-19

Sloyan BM, Kamenkovich IV (2007) Simulation of Subantarctic Mode and Antarctic Intermediate Waters in climate models. J Clim 20:5061-5080

Stark S, Wood RA, Banks HT (2006) Reevaluating the causes of observed changes in Indian Ocean water masses. J Clim 19:4075-4086

Suga T, Talley LD (1995) Antarctic Intermediate Water circulation in the tropical and subtropical South Atlantic. J Geophys Res 100:13441-13453

Sutton RT, Hodson DLR (2005) Atlantic Ocean forcing of North American and European summer climate. Science 309:115-118

Thorpe RB, Gregory JM, Johns TC, Wood RA, Mitchell JFB (2001) Mechanisms determining the Atlantic thermohaline circulation response to greenhouse gas forcing in a non-flux-adjusted coupled climate model. J Clim 14:3102-3116

Vellinga M, Wu PL (2004) Low-latitude freshwater influence on centennial variability of the Atlantic thermohaline circulation. J Clim 17:4498-4511

Wong APS, Bindoff NL, Church JA (1999) Large-scale freshening of intermediate waters in the Pacific and Indian oceans. Nature 400:440-443 